Audiology

\title{
Cochlear implantation in post-lingually deafened adults and elderly patients: analysis of audiometric and speech perception outcomes during the first year of use
}

\author{
L'impianto cocleare nei soggetti ipoacusici postverbali adulti e anziani: \\ analisi dei risultati audiometrici e logopedici nel primo anno di utilizzo
}

\author{
S. GHISELLI', S. NEDIC 1 , S. MONTINO'1, L. ASTOLFI², R. BOVO'1 \\ ${ }^{1}$ Department of Neurosciences, ENT Clinic, Padua University Hospital, Padua, Italy; ${ }^{2}$ Bioacoustics Research \\ Laboratory, Department of Neurosciences, University of Padua, Italy
}

\section{SUMMARY}

The aim of this study was to analyse audiometric and speech perception outcomes after cochlear implantation (CI) in adult and elderly patients in the first year post-CI activation. We evaluated 42 subjects who underwent CI at the Otorhinolaryngological Clinic of Padua Hospital. The subjects enrolled were post-lingually deafened patients who were unilaterally implanted for bilateral, severe-to-profound hearing loss. The overall sample was divided into three groups according to the age at the time of implantation: group A (35-49 years), group B (50-64 years) and group C ( $\geq 65$ years). The subjects were assessed, both before and after surgery (at months 1, 3, 6 and 12), using pure tone audiometry, speech audiometry and speech perception tests and the CAP questionnaire. Statistical analysis of outcomes was using a Student's t-test for paired data. In all study groups a significant improvement was demonstrated in auditory performance examinations post-CI compared to the pre-operative scores. All subjects in all age groups obtained significant improvements in PTA scores before surgery and post-CI activation. Comparison of PTA values among the three age groups did not reveal any significant difference. Considerable improvement was obtained even in the speech audiometry thresholds in all groups at follow-up, with no significant differences between groups. The speech perception examination and CAP questionnaire showed good progress in all study groups, although younger patients tended to achieve more complex categories than older ones. In conclusion, CI is an effective treatment for severe-to-profound hearing loss with no significant differences in auditory performances between older and younger CI recipients. Even if somewhat slower, subjects older than 65 reached good performance and therefore are good candidates for a cochlear implant.

KEY WORDS: Cochlear implant $\bullet$ Hearing loss $\bullet$ Adults $\bullet$ Elderly $\bullet$ Speech perception

\section{RIASSUNTO}

Questo studio è volto alla valutazione degli outcomes audiometrici e logopedici dei pazienti anziani portatori di impianto cocleare durante il primo anno di utilizzo del dispositivo. Sono stati valutati 42 pazienti impiantati tra marzo 2010 e settembre 2014 presso l'UO ORL dell'Azienda Ospedaliera Universitaria di Padova. Sono stati inclusi nello studio pazienti affetti da sordità bilaterale postlinguale di grado severo-profondo impiantati unilateralmente. I soggetti sono stati divisi in tre gruppi in base all'epoca della chirurgia: 14 soggetti con impianto fra i 35 e i 49 anni, 14 fra i 50 e i 64 anni e 14 impiantati a un'età superiore di 65 anni. Tutti i pazienti sono stati valutati prima e dopo la chirurgia (a 1, 3, 6 e 12 mesi di follow-up) attraverso l'esecuzione di: audiometria tonale, audiometria vocale, test logopedici e somministrazione del questionario delle categorie percettive (CAP). L'analisi statistica è stata effettuata attraverso il Student's t-test. La totalità dei soggetti nei tre gruppi hanno dimostrato significativi miglioramenti all'audiometria tonale e vocale ai controlli post chirurgici rispetto alle performance ottenute precedentemente all'impianto. In particolare si sono verificati miglioramenti della soglia audiometrica media (PTA) senza differenze statisticamente significative tra i tre gruppi. risultati ottenuti nei test logopedici e dalla somministrazione del CAP hanno dimostrato evidenti miglioramenti in tutti i tre gruppi in studio. Abbiamo riscontrato, però, che i soggetti più giovani hanno raggiunto maggiori punteggi ai controlli post impianto rispetto a quelli più anziani. Concludendo, possiamo affermare che l'impianto cocleare è un trattamento efficace per soggetti affetti da ipoacusia severa-profonda senza differenze significative nelle performance audiologiche e logopediche in relazione all'età di impianto. Anche se più lentamente, i pazienti impiantati dopo i 65 anni di età raggiungono performance ottimali e possono essere ritenuti dei candidati ottimali all'intervento.

PAROLE CHIAVE: Impianto cocleare $\bullet$ Ipoacusia $\bullet$ Adulti $\bullet$ Anziani $\bullet$ Percezione linguistica

Acta Otorhinolaryngol Ital 2016;36:513-519 


\section{Introduction}

Hearing loss is one of the most frequent chronic disabilities with important medical and psychosocial implications. Recently, the World Health Organization (WHO) has estimated that approximately $15 \%$ of the world's adult population has some degree of hearing loss (HL) and 5.3\% (360 million) suffer from disabling hearing loss (DHL) ${ }^{1}$. The ISTAT (Italian National Institute of Statistics) estimated that $12 \%$ (8 million) of Italians have hearing disorders and $1.2 \%$ suffer from severe to profound deafness ${ }^{2}$. The literature is in agreement that the magnitude of hearing impairment increases with age: according to WHO data, approximately one-third of the world's population above 65 years is affected by DHL. The number of people suffering from hearing disorders is also growing due to the increasing global population and extended life expectancies.

The interest on hearing impairment should expand beyond the epidemiological data to take into account the broad psychophysical and social factors that are likely to be impacted by hearing loss and which might lead to a significant decrease in quality of life ${ }^{34}$.

In a longitudinal study by $\mathrm{Li}$ et al., it was shown that there is a significant association between HL and depression among US adults of all ages, and in particular the prevalence of depression is higher in woman aged 70 years or older ${ }^{3}$.

A recent paper by Amieva et al. reported that $\mathrm{HL}$ has a significant impact on cognitive decline ${ }^{4}$. In particular, self-reported HL in individuals $\geq 65$ years is related to a lower Mini-Mental-State Examination (MMSE) score and major cognitive decline over 25-years of follow-up. Furthermore, a difference in cognitive decline was observed between individuals with HL not using hearing aids (HA) and a control group, while there was no difference between deaf subjects with HA and controls.

When hearing loss progresses beyond the ability of a HA, cochlear implantation (CI) has been shown to be an effective treatment for individuals with severe-to-profound hearing loss.

In adults, CI is often used in case of sudden hearing loss after middle ear surgery ${ }^{5}$ or deafness after acoustic or vestibular neuroma surgery ${ }^{6}$.

It has been demonstrated that CI improves speech perception performances as well as the quality of life in both younger and older patients ${ }^{7-11}$. In a retrospective study, Lachowska et al. reported that the age of patients at the time of CI should not be a negative predictive factor of outcomes ${ }^{7}$. They demonstrated a significant improvement in pure-tone audiometry, speech audiometry, speech perception tests and in quality of life in the post-lingually deafened elderly (aged $\geq 65$ years) assessed during a period of 2 years post-CI.

Castiglione et al. also showed the benefits of CI among patients $\geq 65$ years, showing significant gains in hearing threshold and speech perception outcomes between preoperative and post-operative assessment ${ }^{8}$.

In agreement, in a retrospective study by Park et al., it was shown that age should not be a limitation for CI candidacy ${ }^{9}$. The authors reported that speech recognition and quality of life after CI improve significantly and to similar extents in all age groups examined (age $<50,50-65$, $>65)$.

In a work by Mancini et al., no significant differences were seen in speech perception outcome (both in quiet and in noise) between young and old patients with $\mathrm{CI}{ }^{10}$. Even though younger individuals tended to achieve better scores, as far as the quality of life is concerned, both groups achieved a good level of personal autonomy after CI, even if patients $>65$ were more satisfied with the use of CI.

Moreover, Hilly et al. showed that the audiometric outcome and quality of life of elderly CI patients remains stable over time (over a minimum of 5 years follow-up) ${ }^{11}$. The aim of our study was to assess audiometric and speech perception outcomes in implanted elderly subjects during the first year of CI use. In particular, we evaluated the difference between younger and older CI recipients ( $<65$ years and over 65 years) and the age of implantation as a predictive factor of CI efficacy.

\section{Materials and methods}

\section{Patients}

The medical records of 42 patients undergoing cochlear implant surgery from March 2010 to September 2014 at the ENT Clinic of University Hospital of Padua (Italy) were retrospectively examined in accordance with Italian privacy and sensible data laws (D.lgs 196/03) and to the ENT Clinic of University Hospital of Padua internal policies.

Patient selection criteria are reported in Table I. The 42 patients were divided into three groups according to the

Table I. Inclusion and exclusion selection criteria.

\begin{tabular}{ll} 
Inclusion criteria & Exclusion criteria \\
\hline Post-lingual $\mathrm{HL}$ & Prelingual $\mathrm{HL}$ \\
Bilateral $\mathrm{HL}$ & Monolateral $\mathrm{HL}$ \\
Severe-to-profound $\mathrm{HL}$ & Mild-moderate $\mathrm{HL}$ \\
Time of implantation: > 35 years & $\begin{array}{l}\text { Presence of neurodegenerative } \\
\text { disorders or other pathologies }\end{array}$ \\
Absence of neurodegenerative & associated with HL \\
disorders or other pathologies & Non-use of $\mathrm{HA}$ before implantation \\
associated with HL & Bilateral $\mathrm{Cl}$ \\
Use of HA before implantation & Primary language: other languages \\
Unilateral Cl & Absence of speech and language \\
Primary language: Italian & therapy after Cl \\
Speech and language therapy & \\
after Cl & \\
\hline
\end{tabular}


Table II. Patient characteristics by group.

\begin{tabular}{|c|c|c|c|}
\hline & Group A & Group B & Group C \\
\hline \multicolumn{4}{|l|}{ No. of patients } \\
\hline Female & 9 & 8 & 6 \\
\hline Male & 5 & 6 & 8 \\
\hline Total & 14 & 14 & 14 \\
\hline Age & $45.42 \pm 5.41$ & $61.42 \pm 3.05$ & $74.07 \pm 4.15$ \\
\hline $\mathrm{Cl}$ age & $42.28 \pm 5.39$ & $58.85 \pm 3.32$ & $71.14 \pm 3.91$ \\
\hline $\mathrm{HL}$ years & $27.07 \pm 11.22$ & $28.14 \pm 14.28$ & $27 \pm 14.42$ \\
\hline \multicolumn{4}{|l|}{ Aetiology } \\
\hline Otosclerosis & 4 & 3 & 6 \\
\hline Cholesteatoma & 3 & 3 & 1 \\
\hline Acoustic trauma & 1 & 0 & 0 \\
\hline Unknown & 6 & 8 & 7 \\
\hline \multicolumn{4}{|l|}{ Side implanted } \\
\hline Right ear & 10 & 7 & 6 \\
\hline Left ear & 4 & 7 & 8 \\
\hline \multicolumn{4}{|l|}{$\mathrm{Cl}$ brand } \\
\hline MED-EL & 10 & 6 & 6 \\
\hline Cochlear & 1 & 1 & 3 \\
\hline Advanced bionics & 3 & 7 & 5 \\
\hline
\end{tabular}

Age: mean age at present time expressed in years \pm standard deviation (SD); Cl age: mean age at the time of implantation expressed in years $\pm S D ; H L$ years: mean duration of learing loss at the time of implantation expressed in years $\pm S D$.

age of implantation: group A (35-49 years), group B (5064 years) and group C ( $\geq 65$ years). Each group was composed of 14 subjects with monolateral cochlear implant (in worse ear) and contralateral HA. Patient characteristics are summarised in Table II.

\section{Study design}

Speech and auditory tests were performed pre- and postsurgery and follow-up evaluations were done after 1,3 , 6 and 12 months. Pre-surgical examinations were performed both with and without HA. Patients were assessed in quiet and without lip-reading using a set of audiometric and speech perception tests.

The auditory benefit of the CI was assessed in terms of free-field hearing threshold by measuring the Pure-Tone Average (PTA) expressed in decibels (dB HL) and corresponds to the average air-tonal threshold at the frequencies 500, 1000 and $2000 \mathrm{~Hz}$.

The speech audiometry test was performed by of the Speech Audiometry, Disyllabic Words for Adults test ${ }^{12}$, allowing us to verify the Speech Detection Threshold (SDT), the Speech Recognition Threshold (SRT) and patients' best discrimination score (PB). SDT corresponds to the lowest hearing level (expressed in decibels) at which the patient is able to distinguish the spoken word $50 \%$ of the time. SRT corresponds to the lowest hearing level at which the patient is able to correctly repeat $50 \%$ of a list of words. PB corresponds to the hearing level at which the patient is able to correctly repeat $100 \%$ of a list of words. Speech perception test was performed using the Cochlear Implantation Protocols for selection and evaluation of adults ${ }^{13}$. The evaluation was conducted employing live voice at the sound intensity of $60 \mathrm{~dB}$, and the speech material selected were vowels and disyllabic words, while the results refer to three main categories: detection, identification and comprehension. Detection corresponds to the identification of vowels percentage score $(\mathrm{idv} \%)<80 \%$ and in disyllabic words percentage score $(\mathrm{dsw} \%)<50 \%$. Identification correspond to $\mathrm{idv} \%>80 \%$ dsw $\%>50 \%$. Comprehension correspond to $\mathrm{idv} \%>80 \%$, dsw $\%>50 \%$ and the comprehension of the disyllabic words percentage score $>50 \%$.

Patient performance was also classified by an evaluation questionnaire: Categories of Auditory Performance (CAP) ${ }^{14}$. CAP is composed of eight levels of skills that increase in difficulty, from no awareness of environmental sounds (category 0) to telephone use with a known speaker (category 7).

\section{Statistical analysis}

For speech or auditory tests, average values and standard deviations were calculated and divided by group age. Concerning outcomes evaluation among age groups, the Student's $t$-test for paired data was used. Statistically significant differences were considered with a $p<0.05$. Statistica 7 (StatSoft s.r.l. Italy, 2005) software was used.

\section{Results}

In each study group almost half of patients had hearing loss of unknown causes: $43 \%$ in group A, $57 \%$ in group B and $50 \%$ in group C. The main HL aetiology was otosclerosis with an incidence of $29 \%$ in group A, 22\% in group B and $43 \%$ in group C, while cholesteatoma and acoustic trauma were present to a lesser degree.

All patients, before surgery, were affected by profound HL in the worse ear (ear candidate for CI) and showed poor benefits from HA (PTA threshold shift $=$ about $32 \mathrm{~dB}$, respectively $A=36, B=31$ and $C=30 \mathrm{~dB}$ ) (Fig. 1). Similar results were obtained evaluating the better ear (data not reported). All subjects according to age groups received significant improvement $(\mathrm{p}<0.001)$ considering the PTA scores before surgery (both with and without HA) and those achieved at 1, 3,6 and 12 months post-CI activation. Comparison of PTA values between the three age groups at all experimental times did not show any significant difference $(p>0.05)$ (data not reported).

Concerning speech audiometric examination, all patients reached SDT before and after CI (Table III). Comparing 


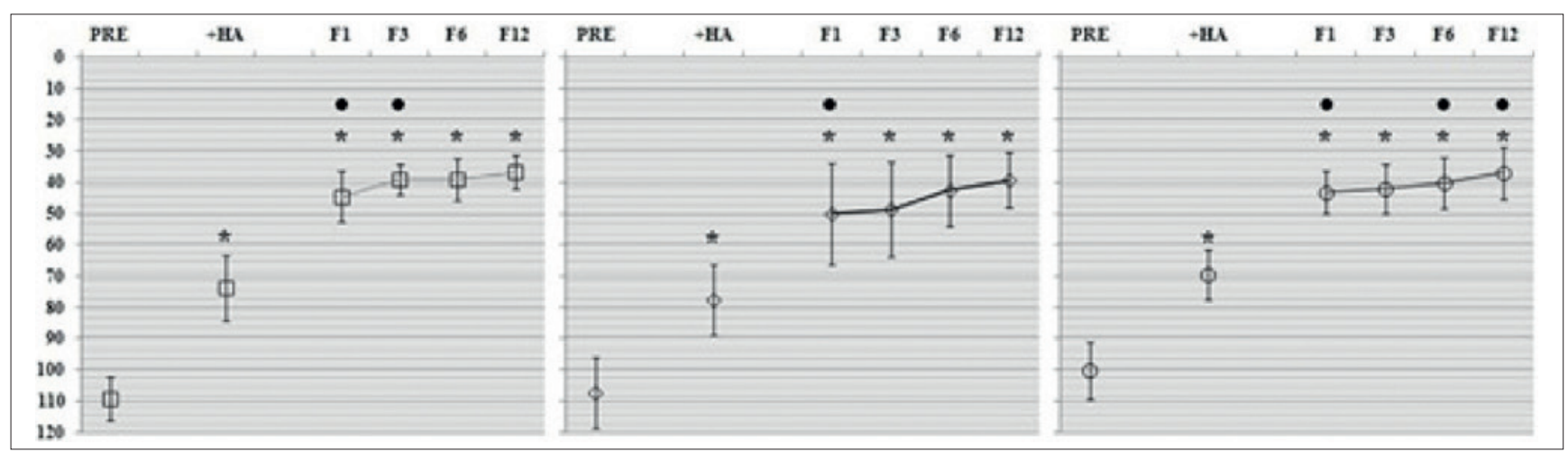

Fig. 1. Pure-tone average expressed in decibels hearing level $(\mathrm{dB} \mathrm{HL}) \pm$ standard deviation (SD).

$P R E=$ pre-surgery PTA without hearing aids; HA= pre-surgery PTA with hearing aids; $F 1=P T A$ at 1 month after activation; F3=PTA at 3 months after activation; F6= PTA at 6 months after activation; F12 $=$ PTA at 12 months after activation; ${ }^{*}=p<0.001$, significant paired $t$ test between PRE and other times; $\bullet=p<0.001$, significant paired $t$ test between each follow-up time and the previous one.

Table III. Pre-operative and post-operative speech audiometry thresholds expressed in $\mathrm{dB}$ of $\mathrm{HL}$ in the three age groups.

\begin{tabular}{|c|c|c|c|c|c|c|}
\hline & \multicolumn{2}{|l|}{ Group A } & \multicolumn{2}{|l|}{ Group B } & \multicolumn{2}{|l|}{ Group C } \\
\hline & $\mathrm{dB} H \mathrm{H}$ & $\mathrm{N}$ & $\mathrm{dB} H \mathrm{HL}$ & $\mathrm{N}$ & $\mathrm{dB} \mathrm{HL}$ & $\mathrm{N}$ \\
\hline \multicolumn{7}{|l|}{ SDT } \\
\hline PRE & $99 \pm 6.33$ & 14 & $94 \pm 5.25$ & 14 & $98 \pm 5.44$ & 14 \\
\hline $\mathrm{HA}$ & $75 \pm 8.19$ * & 14 & $72 \pm 5.78$ * & 14 & $79 \pm 8.12^{*}$ & 14 \\
\hline $1 \mathrm{M}$ & $47 \pm 12.65^{\text {*十 }}$ & 14 & $51 \pm 9.75^{\text {*十 }}$ & 14 & $48 \pm 14.39$ *十 & 14 \\
\hline $3 \mathrm{M}$ & $40 \pm 9.61$ * & 14 & $46 \pm 9.92$ * & 14 & $43 \pm 16.10$ * & 14 \\
\hline $6 \mathrm{M}$ & $38 \pm 8.92$ * & 14 & $40 \pm 12.47$ * & 14 & $40 \pm 14.15^{*}$ & 14 \\
\hline $12 \mathrm{M}$ & $32 \pm 8.93^{\text {* }}$ & 14 & $34 \pm 10.08$ * & 14 & $34 \pm 12.83$ * & 14 \\
\hline \multicolumn{7}{|l|}{ SRT } \\
\hline PRE & I & 0 & I & 0 & l & 0 \\
\hline $\mathrm{HA}$ & $94 \pm 2.50$ & 4 & $94 \pm 4.92$ & 6 & $98 \pm 2.89$ & 3 \\
\hline $1 \mathrm{M}$ & $66 \pm 10.69^{\dagger}$ & 7 & $62 \pm 12.77^{\dagger}$ & 9 & $75 \pm 7.07^{\dagger}$ & 4 \\
\hline $3 \mathrm{M}$ & $57 \pm 8.45^{\dagger}$ & 11 & $65 \pm 15.00$ & 11 & $64 \pm 10.83$ & 9 \\
\hline $6 \mathrm{M}$ & $55 \pm 12.00$ & 14 & $55 \pm 14.91^{\dagger}$ & 11 & $59 \pm 11.45$ & 12 \\
\hline $12 \mathrm{M}$ & $48 \pm 7.78$ & 14 & $51 \pm 11.63$ & 14 & $55 \pm 11.84$ & 14 \\
\hline \multicolumn{7}{|l|}{ PB } \\
\hline PRE & I & 0 & I & 0 & I & 0 \\
\hline $\mathrm{HA}$ & I & 0 & I & 0 & I & 0 \\
\hline $1 \mathrm{M}$ & / & 0 & l & 0 & l & 0 \\
\hline $3 \mathrm{M}$ & I & 0 & I & 0 & l & 0 \\
\hline $6 \mathrm{M}$ & 70 & 1 & $63 \pm 5.77$ & 3 & $75 \pm 7.07$ & 2 \\
\hline $12 \mathrm{M}$ & $65 \pm 5.47$ & 5 & $65 \pm 5.77$ & 4 & $70 \pm 0.00$ & 2 \\
\hline
\end{tabular}

Speech audiometry thresholds expressed in decibels hearing level (dB HL) \pm standard deviation (SD); PRE= pre surgery without hearing aids; HA: pre surgery with hearing aids; $1 M=$ thresholds at the first month after activation; $3 M=$ thresholds at the 3TH month after activation; $6 \mathrm{M}=$ thresholds at the $6 \mathrm{TH}$ month after activation; $12 \mathrm{M}=$ thresholds at the $12 \mathrm{TH}$ month after activation; ${ }^{*}=p<0.001$, high significant paired t test between PRE and other times; ${ }^{\dagger}=p<0.001$, high significant paired $t$ test between each time and the previous one. pre-operative performance scores (with and without HA) and post-activation outcomes after 1, 3, 6 and 12 months, all patients in the three groups showed significant improvement $(\mathrm{p}<0.05)$. Comparisons of the SDT values reached after CI between groups revealed no statistically significant differences $(\mathrm{p}>0.05)$ in performance.

No patient in the overall sample achieved SRT before surgery without HA; using HA, the SRT was achieved by 4 of 14 patients in group A, 6 patients in group B and 3 patients in group C. From qualitative analysis of outcomes, there was an upward trend in all three groups.

Among the youngest group of patients (35-49 years), 7 cases reached SRT in the first month after activation, 11 after 3 months of follow-up and the entire group after 6 months. SRT was achieved by 9 patients in group B and 4 in group $C$ in the first month after activation; 11 patients in group B and 9 in group $\mathrm{C}$ after 3 months and 11 cases in group B and 12 in group $\mathrm{C}$ after 6 months. All patients reached SRT at 12 months of follow-up.

Statistical comparisons of performance scores showed no significant difference $(\mathrm{p}>0.05)$ between groups.

Before CI, none of the subjects achieved a level of $100 \%$ of intelligibility (both with and without HA). The same result was achieved at the first and third month after activation. At 6 months post-CI activation, only 6 patients in the entire sample ( 1 in group A, 3 in group B and 2 in group C) were able to correctly repeat $100 \%$ of words. At 12 months post-CI activation, $100 \%$ of intelligibility was reached by 5 subjects in group A, 4 in group B and 2 in group C.

Figure 2 shows the speech perception evaluation before the cochlear implant and at 1, 3,6 and 12 months after activation. Before CI in unaided conditions, none of the patients achieved detection, whereas with $\mathrm{HA}$ the results were reached by 7 individuals in group A, 8 in B and 6 in C. At the first month of follow-up, 2 patients in groups $\mathrm{A}$ and $\mathrm{C}$ and 5 in $\mathrm{B}$ achieved the best category (comprehension); identification was achieved in 6 cases in group A, 3 in group B and 2 in group C. Six patients in groups A and B 


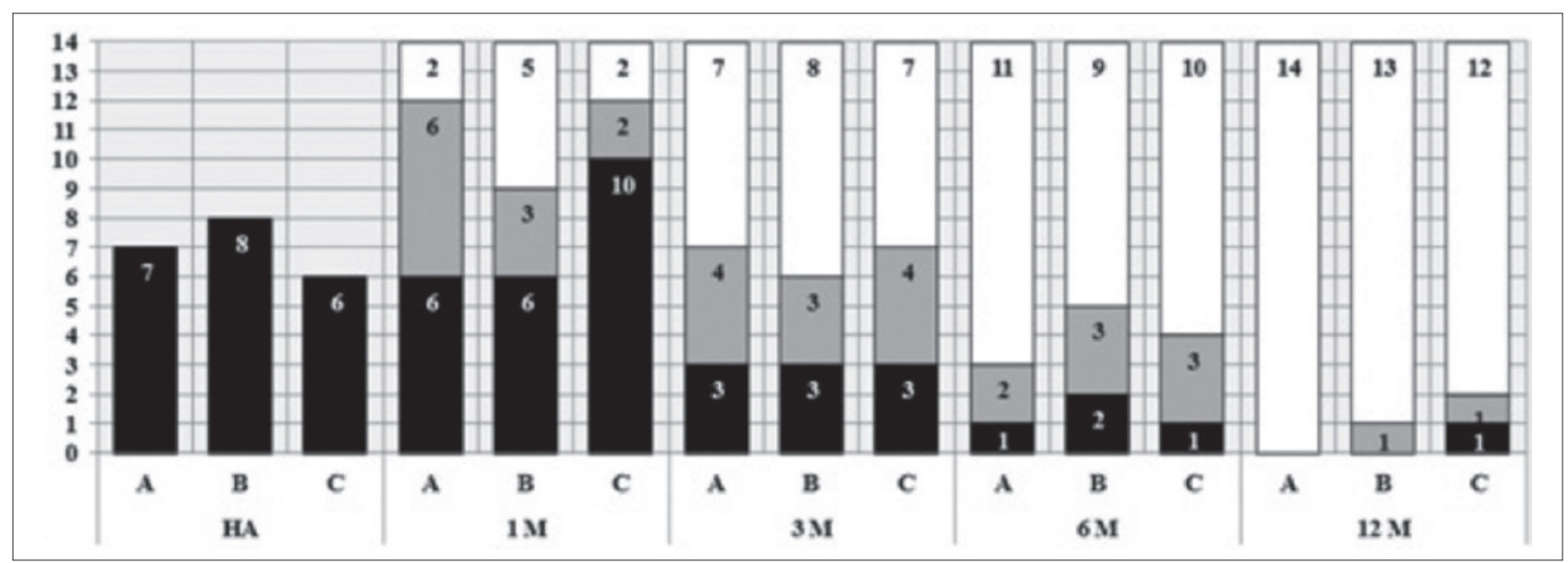

Fig. 2. Number of patients that achieved the three different speech perception categories according to age at the different experimental times.

$H A=$ pre-surgery with hearing aids; $1 M=1$ month after activation; $3 M=3$ months after activation; $6 M=6$ months after activation; $12 M=12$ months after activation; black color= detection, grey color= identification, white color= comprehension .

and 10 in group $\mathrm{C}$ reached only the category of detection. At 3 months after activation, 7 patients in groups $\mathrm{A}$ and $\mathrm{C}$ and 8 in group $\mathrm{B}$ achieved comprehension; 4 patients in groups $\mathrm{A}$ and $\mathrm{C}$ and 3 in group $\mathrm{B}$ achieved identification. At 6 months post-activation, the number of patients who reached comprehension was: 11 subjects in group $A, 9$ in group $\mathrm{B}$ and 10 in group $\mathrm{C}$. Eight subjects in the entire sample ( 2 in group A, 3 in group B and 3 in group C) achieved identification.

At 12 months of follow-up, the comprehension category was achieved by all patients in group A, 13 in group B and 12 in group $\mathrm{C}$. Only 2 subjects ( 1 in group $\mathrm{B}$ and 1 in group $\mathrm{C}$ ) reached the identification category and only one patient in group $\mathrm{C}$ achieved the detection category.

All patients were also evaluated by Categories of Auditory Performance (CAP) before and after surgery (Fig. 3). Be- fore surgery, all groups were collocated in categories 0 and 1 if examined in unaided conditions and between categories 1 and 2 if assessed using HA. After 1 month, all patients in group $\mathrm{C}$ gained category 2 and few patients in groups $\mathrm{A}$ and B achieved category 4 . Achievements increased significantly over time and no significant differences were found between groups: improved results were observed in both the youngest (group A) and elderly (group C) patients.

\section{Discussion}

The literature agrees that use of CI, both in adult and elderly subjects, leads to significant improvement in audiological tests and speech perception scores 7810111516192122 . Furthermore, it is well known that cochlear implant improves the quality of life 791523 .

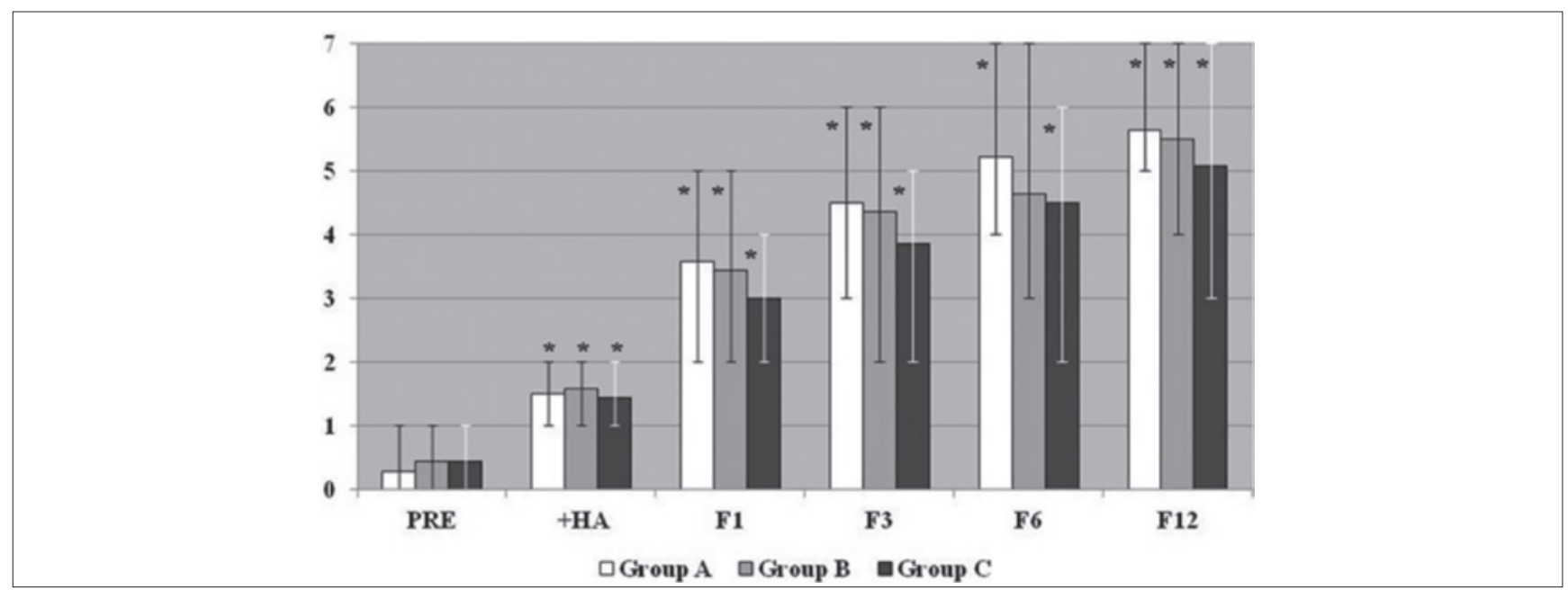

Fig. 3. Mean values obtained with the CAP questionnaire during post-operative follow-up.

Bars indicated the min and max values. * paired $t$ test, $p$-value $<0.01$ between each follow-up time and the previous one by group. 
In agreement, in our study, since the first month postactivation, all implanted subjects showed improvements in audiological (hearing threshold and speech audiometry) and speech perception tests. In particular, when we evaluated PTA, SDT (speech audiometry) and CAP, a significant correlation was found between pre-surgery stage (with and without hearing aids) and different follow-up times in all three groups.

In the first month of CI use, all patients made good improvement in all tested categories (both audiological and speech score). Major progresses were reached in speech audiometry tests: most patients reached the categories of identification and comprehension, whereas before implantation, all subjects achieved only the detection category.

Differently from Budenz et al, the studies of Holden et al. and Lin et al., we can assert that the performance of our subjects in speech tests are not correlated to the age of implantation ${ }^{16-18}$.

It is interesting to note that outcome improvement was seen in all our three groups, but to different degrees. The elderly group reached similar audiometrical and speech results as the other two groups, albeit slower. Looking at the outcomes of the elderly group at 12 months post-activation, patients reached the same PTA as the other two groups, but with persistent, small differences in performance in speech perception tests.

Different studies have analysed the factors affecting postlinguistic performance in implanted adults.

Some have shown that the use of a hearing aid before implantation influences auditory performance ${ }^{19}{ }^{20}$, whereas Park et al. have reported that the use of HA pre-implant had no substantial effect on patient performance or speech recognition ${ }^{9}$.

In our study, since all subjects in the three groups used HA before implantation, we can suppose that the mild delay seen in performance in elderly patients was not correlated to the use of pre-surgery HA, in accordance with Park, but we cannot support this possibility due to the lack of comparison with a non-HA group.

Lazard et al. also reported that CI brand significantly influenced speech performance of implanted adults ${ }^{20}$. In our study, patients used three different CI brands (22 patients with Medel, 5 with Cochlear and 15 with Advanced Bionics), but the sample is too small and inhomogeneous to show any correlation between brand and other factors analysed.

Some authors affirmed that speech perception outcome in elderly implanted patients is significantly lower in difficult noisy conditions ${ }^{181921}$. In our study, all speech perception tests were performed in quiet conditions.

Further prospective studies will be required to evaluate the performance of our subjects in noisy conditions.

\section{Conclusions}

In the present study, pure tone audiometry, speech audiometry, speech perception tests and CAP questionnaire revealed that there is a variability in auditory performances across study groups. In fact, no significant difference was seen in outcomes with CI between the three age groups. On the other hand, we observed that outcomes are achieved slower in older patients than in younger ones. Our results add additional support to the hypothesis that CI is an effective treatment for severe-to-profound HL and that the age of the subjects at time of implantation should not be considered as a limiting factor.

We can assert that, even if slower, subjects older than 65 years attain good performances and therefore are good candidates for a cochlear implant.

\section{Acknowledgements}

We are very grateful to Stella Montino and Prof. Alessandro Martini for their collaboration.

\section{References}

1 World Health Organization. Global estimates on prevalence of hearing loss. Geneva, Switzerland: World Health Organization 2012 (http://www.who.int/pbd/deafness/WHO_GE_ HL.pdf?ua=1).

2 Altissimi G, Giacomello P, Mazzei F, et al. Deafness in Italy: an epidemiological and socio-demographic study. Eur Rev Med Pharmacol Sci 2014;18:1533-43.

3 Li CM, Zhang X, Hoffman HJ, et al. Hearing impairment associated with depression in US adults, National Health and Nutrition Examination Survey 2005-2010. JAMA Otolaryngol Head Neck Surg 2014;140:293-302.

4 Amieva H, Ouvrard C, Giulioli C, et al. Self-reported hearing loss, hearing aids, and cognitive decline in elderly adults: a 25-year study. J Am Geriatr Soc 2015;63:2099-104.

5 Vincenti V, Pasanisi E, Bacciu A, et al. Cochlear implantation in chronic otitis media and previous middle ear surgery: 20 years of experience. Acta Otorhinolaryngol Ital 2014;34:272-7.

6 Dagna F, Murri A, Albera R, et al. Coclear implantation in delayed sudden hearing loss after conservative vestibular schwannoma surgery. Acta Otorhinolaryngol Ital 2016;36:428-30.

7 Lachowska M, Pastuszka A, Glinka P, et al. Is cochlear implantation a good treatment method for profoundly deafened elderly? Clin Interv Aging 2013;8:1339-46.

8 Castiglione A, Benatti A, Girasoli L, et al. Cochlear implantation outcomes in older adults. Hear Bal Commun 2015;13:86-8.

9 Park E, Shipp DB, Chen JM, et al. Postlingually deaf adults of all ages derive equal benefits from unilateral multichannel cochlear implant”. J Am Acad Audiol 2011;22:637-43.

10 Mancini P, Ballantyne D, Di Mario A, et al. Benefit of prosthetic cochlear implant in the elderly with moderate/severe hearing impairment. Italian J Geriatr Gerontol 2014;2:11-6. 
11 Hilly O, Hwang E, Smith L, et al. Cochlear implantation in elderly patients: stability of outcome over time. Laryngol Otol 2016;13:1-6.

12 Cutugno F, Prosser S, Turrini M. Audiometria vocale - vol. I. ed. GN. ReSound Italia 2000.

13 Quaranta A, Arslan E, Babighian G, et al. Impianto cocleare. Protocolli di selezione e valutazione dei soggetti adulti. Acta Phoniatrica Latina 1996;18:187-265.

14 Archbold S. Monitoring progress in children at the preverbal stage. In: McCornick B. et al., eds. Cochlear Implants for Young Children. London (UK): Whurr 1994, pp. 197-213.

15 Miller G, Miller C, Marrone N, et al. The impact of cochlear implantation on cognition in older adults: a systematic review of clinical evidence. BMC Geriatr 2015;15:16.

16 Budenz CL, Cosetti MK, Coelho DH, et al. The effects of cochlear implantation on speech perception in older adults. J Am Geriatr Soc 2011;59:446-53.

17 Holden LK, Finley CC, Firszt JB, et al. Factors affecting open-set word recognition in adults with Cochlear implants. Ear Hear 2013;34:342-6.

18 Lin FR, Chien WW, Li L, et al. Cochlear implantation in older adults. Medicine (Baltimore) 2012;91 229-41.

19 Mosnier I, Bebear JP, Marx M, et al. Predictive factors of cochlear implant outcomes in the elderly. Audiol Neurootol 2014;19(Suppl 1):15-20.

${ }^{20}$ Lazard DS, Vincent C, Truy E, et al. Pre-, per- and postoperative factors affecting performance of postlinguistically deaf adults using cochlear implants: a new conceptual model over time. PLoS One 2012;7:e48739.

21 Lenarz M, Sönmez H, Joseph G, et al. Cochlear implant performance in geriatric patients. Laryngoscope 2012;122:1361-5.

22 Schwab B, Gandolfi M, Lai E, et al. The impact of age on Cochlear implant performance. Int J Otolaryngol 2015;4:329-37.

23 Di Nardo W, Anzivino R, Giannantonio S, et al. The effects of cochlear implantation on quality of life in the elderly. Eur Arch Otorhinolaryngol 2014;271:65-73.

Received: April 27, 2016 - Accepted: September 21, 2016

Address for correspondence: Sara Ghiselli, ENT Clinic, Department of Neuroscience, Padua University Hospital, via Giustiniani 2, 35128 Padova, Italy. Tel. +39 049 8211993. Fax +39049 8211994. E-mail: saraghiselli80@gmail.com 